\title{
Assessment of The Impact of Teenage Pregnancy on Pregnancy Outcome among Pregnant Women in Minia University Hospitals, Minia Governorate
}

\author{
${ }^{1}$ Khaled Hussein M. Eldessouki, ${ }^{2}$ Mohammed Abd Elhakim Quodi, ${ }^{3}$ Sanaa Mahmoud \\ Ahmed Hassane. \\ ${ }^{1}$ Department of Public health and preventive medicine, ${ }^{2}$ Department of obstetrics and \\ gynecology Faculty of Medicine, ${ }^{3}$ Department of Pediatrics Nursing, Faculty of Nursing, \\ Minia University, Egypt.
}

\section{Abstract}

Background: Early pregnancy or adolescent pregnancy means women under age of 20 years who are pregnant with their first child. Egyptian studies in 2015 stated that teenage pregnancy rate was 47/1000. The World Bank reported in 2017 that the adolescent fertility rate (15-19 years) in Egypt (was 50 births for every 1000 women. It carries a high risk for both the mother and infant and associated with maternal complications, low birth weight, perinatal mortality and increased infant mortality especially in developing countries like Egypt. Objective: To define if there is an association between young age pregnancy with increased risk of unfavorable pregnancy outcome. To compare pregnancy outcome of adolescent pregnancy (15-19years old) with young adult (20-29 years old) pregnancy. Method: A descriptive comparative hospital-based study is analyzing pregnancy and delivery outcomes of a teenage group 15-19 years compared with an adult group 20-29 years of age in Minia university hospitals Minia governorate. it was held from January 2017 to June 2017. Results: Teenage is associated with preterm birth <37 weeks (14.4\%), low birth weight (12\%), stillbirth $(2.4 \%)$ and antepartum hemorrhage $(14.4 \%)$, cesarean section was done for $(44.8 \%)$ of the teenagers group and Pre-eclampsia in teenagers was $(24.8 \%)$ while in adult group was (11.6\%). Conclusion: Pregnancy before 20 years old is a high-risk pregnancy and leads to unfavorable pregnancy outcome and has a negative impact on maternal and neonatal health.

Keywords: Adolescent pregnancy, Teenage, pregnancy outcome, preterm labor, low birth weight.

Corresponding Author: Khaled Hussein M. Eldessouki ，E-mail: klddsok@gmail.com

\section{Introduction}

Adolescent age starts at puberty and ends when biological, and physical maturity occurs at adulthood age. Adolescent age is defined as a period of the ages from 10 to 19 years. Adolescent pregnancy may associate with adverse pregnancy outcomes as low birth weight, preterm delivery, and neonatal mortality. ${ }^{1}$ Early pregnancy or adolescent pregnancy means women under age of 20 years who are pregnant with their first child. Egyptian studies in 2015 stated that teenage pregnancy rate was $47 / 1000$. The World
Bank reported in 2017 that the adolescent fertility rate (15-19 years) in Egypt (was 50 births for every 1000 women. It carries a high risk for both the mother and infant and associated with maternal complications, low birth weight, perinatal mortality and increased infant mortality especially in developing countries like Egypt. $^{2}$ Young age pregnancy before 20 years old is a significant public health problem as it affects the newborn and maternal safety. ${ }^{3}$ Many studies have stated that pregnancies before the age of 20 years 
have a greater incidence of unfavorable pregnancy outcomes, for example, low birth weight, preterm births, and fetal growth retardation. Complications on young mothers may endanger their life and increase maternal mortality. ${ }^{4}$

Around one million females aged 10-11 years and about 16 million teenager females 15-19 years old give birth every year. Greatest of these pregnancies occurs in developing countries. ${ }^{5}$ The worldwide nations with high prevalence of teenage pregnancy are Nigeria (51\%), Chad (48\%), Mali (46\%), Guinea (44\%), Mozambique (42\%), Bangladesh (36\%), and Madagascar (36\%) (6). In Iceland the rate of teenage pregnancy was $15 \%{ }^{7}$

Adolescent fertility in Egypt, drops from 148 per 1000 women age $15-19$ years in 1960 to 51 per 1000 women age $15-19$ years in 2015. ${ }^{6}$ According to the Population Reference Bureau, adolescent girls represent $20 \%$ of Egypt's population and this group will increase to $44 \%$ in 2030. ${ }^{8}$ According to the Egypt Demographic Health Survey, 2014, it was stated that one in six girls become pregnant at age of 18 years. ${ }^{9}$ Worldwide teenage pregnancy is the second cause of death for teenage females. Annually around 3 million teenager females had risky abortions. ${ }^{5}$ These teenage girls are not physically and psychologically mature enough for reproduction and are not ready yet to be mothers. ${ }^{10}$

Many studies concerning teenage and adolescent female pregnancy outcomes are differing; some revealed high risk of unfavorable outcomes and others didn't. Moreover, studies in developing countries including Egypt, are lacking and there is a need to determine accurately the frequency of adolescents pregnancy and to determine the pregnancy outcome of teenage pregnant women less than 20 years compared with that of older (20-29 years).Pregnancy at a young age before 20 years old is a public health problem especially in developing countries as it often affects the mother and newborn health. ${ }^{11}$ The pregnancy at young age often carrying a great risk for both the mother and pregnancy outcome. The rate of adolescent pregnancy is increased in many countries due to: traditional, social, or cultural reasons. Poverty, limited education and low socioeconomic level are the most significant factors. ${ }^{12}$ The rate of adolescents' pregnancy in developed countries, such as the USA is 54/1000 and in Germany 111/1000. Teenagers' pregnancy rate in developing countries is high and in Egypt 47/1000. Young age pregnancy often combined with poor health care and malnutrition which increase the medical problem in developing countries. ${ }^{13}$

In Egypt, the rate of teenage pregnancy is $4.1 \%$ in urban areas and $11.3 \%$ in rural societies. ${ }^{14}$ The size of the problem is greater in upper Egypt especially rural areas due to traditional early marriage so more early pregnancy and increased rate of pregnancy and natal complications. ${ }^{15}$

The studies regarding teenage and adolescent female pregnancy outcomes are contradictory; some revealed excess possibility of adverse outcomes and others didn't. In addition, studies in Egypt are deficient and there is a need to determine accurately the frequency of teenage pregnancy and to assess the outcome of teenager women pregnancy compared with that of adult (20-29 years).

\section{Objective}

To determine if there is an association between young age pregnancy with increased rate of unfavorable pregnancy outcome. To compare pregnancy outcome of adolescent pregnancy (15-19years old) with young adult (20-29 years old) pregnancy

\section{Method}


Study design: A descriptive comparative hospital-based study was done in Minia governorate is analyzing teenager women pregnancy outcome $(<$ 20years old $)$

Table 1: Demographic Characteristics of Studied Mothers in Minia University Hospitals Minia Governorate from January 2017 to June 2017.

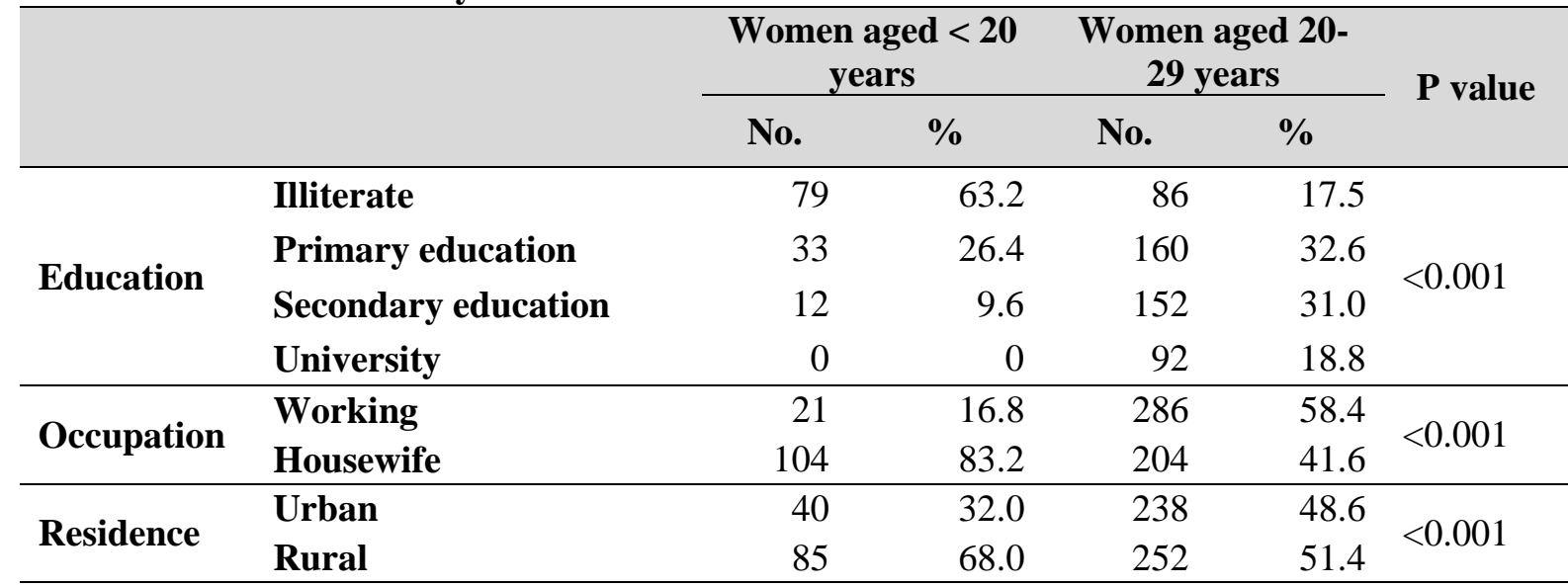

compared with a young adult group 20-29

years of age in obstetric clinics labor and postoperative wards in Minia Maternity University Hospitals Minia governorate. It was held from January 2017 to June 2017.

Sample size and sampling method: Total sample size was 615 pregnant women including 125 cases of teenager pregnant women and 490 adult pregnant women. We take all the cases of nulliparous mother who attended in obstetric clinic for pregnancy follow up and who attended labor and postoperative wards for delivery from January 2017 to June 2017. Data was collected by an interviewing questionnaire to all females who were doing follow up in obstetric clinic during pregnancy and to labor ward attendants at Minia Maternity University Hospital., during the next 6 months from January 2017 to June 2017.

Subjects of the study were divided in to two groups: The study group (includes women with the age of 19 years or less at the time of delivery). The control group (includes women aged more than 19 years at delivery).

Application of an interviewing questionnaire to all women who were followed up during pregnancy and those who were attended the labor ward during the next 6 Months.

Data collection tool: A well-structured questionnaire was prepared which included:

Demographic information and personal characteristics regarding age, residence, marital state, occupation, weight, and prenatal visits. Socioeconomic characteristics which involved education level, family income. Obstetric history including the period of pregnancy, antenatal care, and pregnancy complication, abortion and presentation. Delivery and its complications Including time, mode of delivery, gestational age and any complications. Questions about Fetal and neonatal outcome (birth weight, and the admission to neonates' Intensive care unit reference).

Criteria of inclusion: All nulliparous mothers who had singleton live births under 20 years old ( $1^{\text {st }}$ group) and young adults from $20 y$ to29years old ( $2^{\text {nd }}$ group) who have had no chronic medical disease, overweight or underweight from January 2017 to June 2017 in Minia maternity university hospital

Criteria of exclusion: We excluded from both groups those women with chronic medical disease (hypertension, diabetes, renal, cardiac diseases) and overweight females at the time of first antenatal care 
Khaled H. Eldessouki, et al Assessment of the impact of teenage pregnancy on pregnancy outcome 90

visit (Body mass index >25) and underweight women (BMI $<20 \mathrm{~kg} / \mathrm{m} 2$ ) and Table 2: The Antenatal care received by the studied mothers in Minia university hospitals Minia governorate from January 2017 to June 2017.

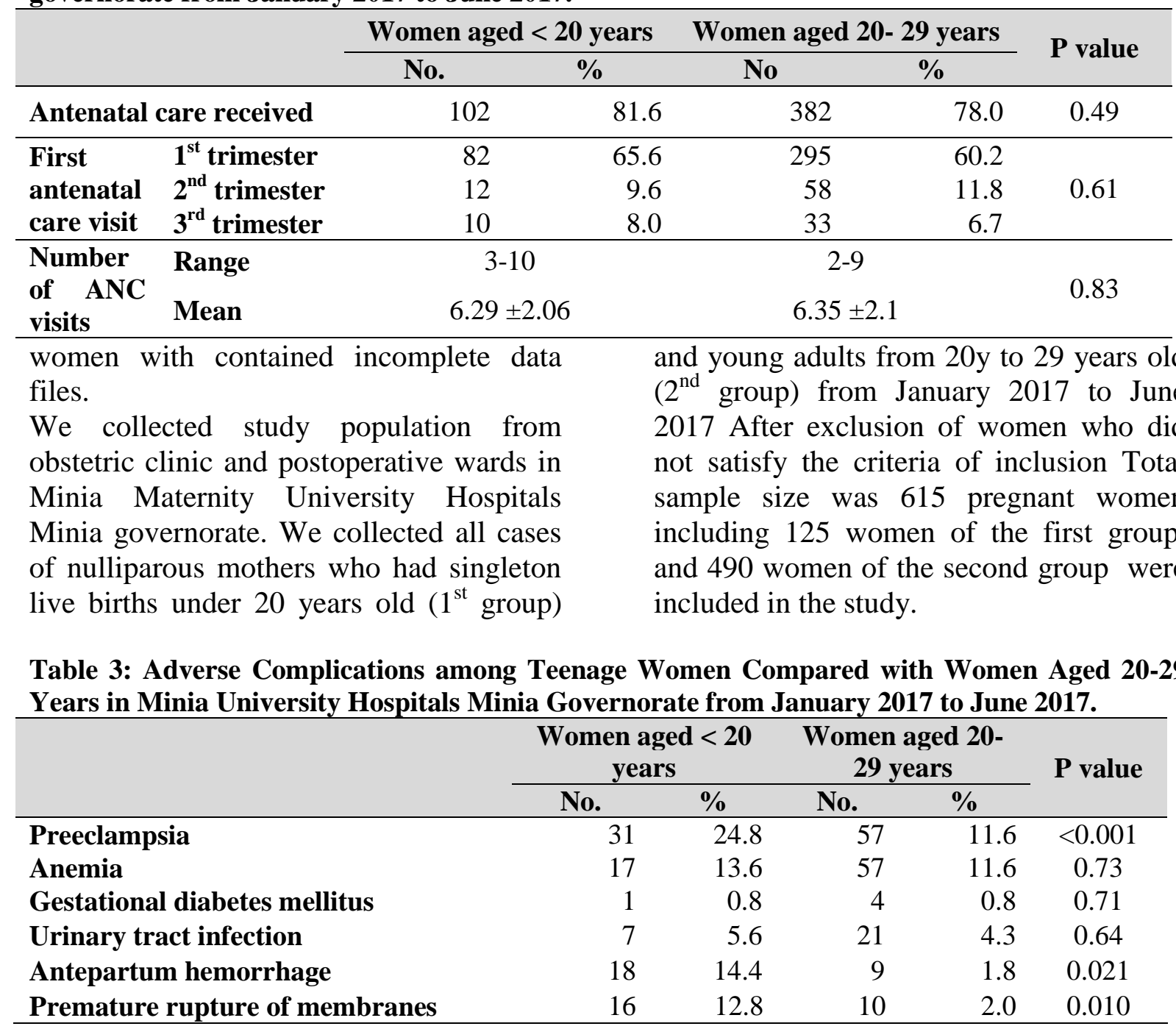

The following definitions were used to Data collected, organized, entered, coded record pregnancy outcomes: preterm birth; delivery before 37 weeks of gestation, and low birth weight (LBW); if neonates weight $<2500$ grams. Pre-eclampsia was diagnosed when blood pressure reached $140190 \mathrm{~mm} \mathrm{Hg}$ or more with increased protein in the urine of the pregnant women (proteinuria).

To test feasibility of the tools and the required time for finalizing the study it was done on 61 cases. These cases were excluded from the study.

\section{Statistical analysis} and analyzed by Statistical package for social sciences version 19 (SPSS).

Mean and standard deviation were used as descriptive value for quantitative data .Qualitative data were presented as percentage and Statistical differences between the two groups were calculated by using $\mathrm{x}^{2}$ tests, and fisher's exact test if the minimal estimated expected value was less than five. We used Unpaired student's test for comparison of quantitative variables. Statistically Significance level: when Pvalue $<0.05$. 
Table 4: Adverse Complications on Delivery among The Teenage Women Compared with Women Aged 20-29 Years in Minia University Hospitals Minia Governorate from January 2017 to June 2017.

\begin{tabular}{|c|c|c|c|c|c|}
\hline & \multicolumn{2}{|c|}{$\begin{array}{l}\text { Women } \\
<20 \text { years }\end{array}$} & \multicolumn{2}{|c|}{$\begin{array}{c}\text { Women } \\
\text { 20- 29 } \\
\text { years }\end{array}$} & \multirow[t]{2}{*}{$P$ value } \\
\hline & No. & $\%$ & No. & $\%$ & \\
\hline $\begin{array}{l}\text { Assisted } \\
\text { vaginal } \\
\text { delivery }\end{array}$ & 69 & 55.2 & 40 & 8.2 & \\
\hline $\begin{array}{l}\text { Caesarean } \\
\text { Section } \\
\text { delivery }\end{array}$ & 56 & 44.8 & 88 & 18 & $<0.001$ \\
\hline $\begin{array}{l}\text { NBICU } \\
\text { admission }\end{array}$ & 39 & 8 & 20 & 4 & $<0.001$ \\
\hline
\end{tabular}

\section{Ethical Consideration}

The approval was acquired from the ethical committee of faculty of medicine Minia University; also approvals were obtained from the Minia university hospital manager and the head of department of obstetrics and gynecology. The release of this information is allowed by legalization for research studies. No names or personal information were used to keep the patient's confidentiality.

\section{Results}

This study included 125 teenage pregnant females and 490 pregnant women aged more than 20 years (middle age women), out of the pregnant women attending in Minia Maternity University Hospital, in the period from January 2017 to June 2017 after we excluded women with incomplete data or Presence of disease before pregnancy or being overweight or underweight . They were (125) adolescent women were compared to (490) nulliparous mothers aged 20 -29 years and had singleton births

Regarding the age of the 2 groups after exclusion of women who were not satisfy the criteria of inclusion 125 women of the first group, (with mean age of $17.4 \pm 1.4$ ) and 490 women of the second group with mean age of $(24.2 \pm 3.3)$ years were included in the study Concerning the age distribution of the adolescent mother, [5.0\%] were aged below 16 years, [6.0\%] aged 16 years [15.3\%] aged 17 years, [25.4\%] aged 18 years and [48.3\%] aged 19 years.

Demographic data of the studied 2 women groups showed that comparable demographic finding, regarding education level, occupation, and residence, with a highly significant difference between the two groups (Table 1).

About the antenatal care, no significant difference was found between Women < 20 years and those more than 20 years as shown in (Table 2).

Table 5: Adverse Complications on The Neonates of Teenage Women Compared with Women Aged 20-29 Years in Minia University Hospitals Minia Governorate from January 2017 to June 2017.

\begin{tabular}{|c|c|c|c|c|c|}
\hline & $\begin{array}{r}\text { W } \\
\text { age } \\
\mathbf{y}\end{array}$ & $\begin{array}{l}\text { nen } \\
<20 \\
\text { res } \\
\end{array}$ & $\begin{array}{l}\text { W } \\
\text { age } \\
29 \\
\end{array}$ & $\begin{array}{l}\text { men } \\
20- \\
\text { ears }\end{array}$ & $\begin{array}{c}\mathbf{P} \\
\text { value }\end{array}$ \\
\hline & No. & $\%$ & No. & $\%$ & \\
\hline $\begin{array}{l}\text { Preterm } \\
\text { delivery }<37 \\
\text { weeks }\end{array}$ & 18 & 14.4 & 40 & 8.2 & $<0.001$ \\
\hline $\begin{array}{l}\text { Low Birth } \\
\text { weight in grams } \\
(<2500 \text { gm) }\end{array}$ & 15 & 12.0 & 29 & 5.9 & $<0.001$ \\
\hline Stillbirth & 3 & 2.4 & 6 & 1.2 & 0.010 \\
\hline $\begin{array}{l}\text { Congenital } \\
\text { anomalies }\end{array}$ & 4 & 3.2 & 0 & 0 & 0.008 \\
\hline
\end{tabular}

Concerning the rate of complications, there was a significantly higher percentage among teenagers to develop all complications than middle-aged females, except anemia, gestational diabetes mellitus, and urinary tract infections, which showed non-significant differences as shown in (Table 3). The preeclampsia, anemia percentage are markedly increased because great proportion of the pregnant 
women who are attending in hospitals for delivery usually already complaining of hypertension or anemia during pregnancy and they are afraid from complications of delivery at home so it differs from community based studies percentage. (This blue paragraph should be transmitted to the discussion )

Comparing the 2 groups revealed a significantly higher percentage among teenagers in assisted vaginal delivery, Caesarean Section, Neonatal Intensive Care Units need. (Table 4)

There was a significantly higher percentage among teenagers to develop adverse complications on the neonates than middle-aged females such as preterm delivery, low birth weight, stillbirth, and neonatal congenital anomalies as presented in (Table 5).

\section{Discussion}

Concerning demographic data of the studied mothers displayed that the education level, about $65 \%$ of the adolescent mothers were illiterates, one quarter had only primary education, and less than $10 \%$ had secondary level of education while in women older than twenty years around $18 \%$ were illiterate, and more than $18 \%$ had university education, with two thirds had either primary or secondary education level which constitutes highly significant difference this reflects the adverse effect of non-education of girls on their health . These findings of education level are going along with these of Fathalla $2007^{21}$ who has pointed to that the adolescent pregnancy is highest among low educated women. Similarly, in a study of Watcharaseranee et al 2006 at chonburi hospital $^{22}$ which establish that teenage mothers had lower levels of education and they received poor antenatal care. Mahavarkar SH et al 2008 in tertiary teaching hospital,in India $^{12}$ established that adolescent pregnancy was significantly more frequent in young mothers who had discontinued their education at the level of primary or preparatory-school.

Only16.8\% of teenage pregnant women were working and more than $80 \%$ were housewives. while only $41.6 \%$ of young adult pregnant mothers were housewives. This difference was, highly significant. Parallel results were stated by Figueiredo et al $2006^{23}$ who found that working mothers were more in the young adult compared to the adolescent group. Regarding residence, $68 \%$ of teenage mothers live in rural areas. In the young adult group, the residence is nearly divided into two equal parts between rural and urban areas which constitute a highly significant difference between the two groups. In correspondence with these results, Fathalla 2007 in Sohag general hospital in Sohag governorate ${ }^{21}$ has told that the level of teenage pregnancy in rural societies is almost twice that in urban areas due to early marriage and pregnancy in rural areas. Also, Fathalla 2007 ${ }^{21}$ study has established that Upper Egypt, has the highest rate of adolescent pregnancy.

As regards the most common adolescent pregnancy complications, was preeclampsia which, perceived in $24.8 \%$ of cases and the next was preterm labor $(14.4 \%)$. There was a significantly lower possibility among young adult women compared to teenagers to develop all complications, except anemia, gestational diabetes, and urinary tract infections. Concerning pre-eclampsia, our results are going along with that stated by Mahavarkar SH et al 2008 in tertiary teaching hospital,in India. ${ }^{12}$ Another study by Kongnyuy EJ. Et al 2008 in Cameroon revealed an increased proportion of preeclampsia in adolescent mothers. ${ }^{25}$ These findings differed with what is stated by Al-Ramahi et al 2006 at a university 
hospital in Jordan which reported a similar or lower incidence of preeclampsia rates among teenagers. ${ }^{24}$ Some studies described a significantly increased possibility of these complications in adolescent pregnant women by Ziadeh $S$ et al.2001 in North Jordan $^{26}$ and Yildirim $Y$ et al 2005. in Turkish women. ${ }^{27}$

About $55.2 \%$ of adolescent pregnant women submitted to assisted vaginal delivery, with $44.8 \%$ had a Caesarean Section operation with a significant difference from the adult mothers, who required Caesarean Section in $18 \%$ of cases. This study finding disagrees with that stated by Maryam and Ali in teenagers in East Sauterne of Iran $2008^{28}$ and goes along with that established by Mahavarkar SH et al 2008 in tertiary teaching hospital, in India ${ }^{12}$ who reported a higher incidence of cesarean section rate in the teenage group. Preterm delivery $(14.4 \%)$ in teenage mothers and $8.2 \%$ in the adult group).With a significant difference which goes along with Chen et al 2008. ${ }^{29}$

Low Birth weight rate increased significantly in the teenage group. These results are compatible with studies which demonstrated an increased possibility of low birth weight as a result of the young age of the mother by Chen et al.2007 in United States $^{30}$, Ali M. et al. in Ethiopia's Tikur Anbessa Hospital 1997. ${ }^{32}$ Congenital anomalies occurred in $3.2 \%$ and stillbirths occurred in $2.4 \%$ of cases, in the adolescent group, while $1.2 \%$ for stillbirth and non for congenital anomalies in the middle age group, both show a significant difference. Chen et al.2007 $7^{30}$ reported increased possibilities of congenital anomalies in the teenage group.

\section{Conclusion}

Pregnancy before 20 years old is a highrisk pregnancy and leads to unfavorable pregnancy outcome and has a negative impact on maternal and neonatal health.
Physicians and healthcare workers should be attentive that adolescent pregnancies are high-risk pregnancies and tell pregnant teenagers about that risk and instruct them for good and complete antenatal care. Pregnant young girls are more predisposed to preeclampsia, pre-term labor, having low birth weight babies. Pregnant teenagers are more expected to be unschooled, illiterate, not working and from rural areas; this increases the impact on teenage pregnancy and worsens the problem.

\section{Recommendations}

Regulatory health education programs should be conducted for youth and their parents about the psychological, social, and medical hazards of early marriage and early pregnancy.

Applying training courses for primary health care doctors, family physicians, and nurses about the proper support and appropriate dealing with teenage pregnancy.

Further larger studies should be done nationally with the collaboration of ministry of health and population.

Merits and values of the study: The study covered a reasonable sample of teenage and adult pregnant women for 6 months at the busiest renowned hospital of Minia University at Minia Governorate. There are no unresolved problems in collecting data and the nurse team was very cooperative.

\section{Study Limitations}

This is a tertiary hospital-based study and the results should be considered with cautious when we want to generalize it to the community. Possibly many teenagers cannot attend the hospital due to poverty or absence of transportation.

Administrative approvals were not so easy and time consuming. 
Data collection process was challenging as done in a very crowded busy area in the hospital distracting the attention and consuming the time.

The financial resources were scarce because there was no financial support from anyone.

\section{Acknowledgements}

The authors express their thanks and gratitude to the nursing staff of Minia University hospital for pediatrics, gynecology, and obstetrics that facilitated carrying out of the study.

Financial support and funding: There was no financial support from anyone.

Conflicts of interest: There are no conflicts of interest.

\section{References}

1. Klein JD, American Academy of Pediatrics Committee on A. Adolescent pregnancy: current trends and issues. Pediatrics. 2015;116(1):281-6.

2. World Bank report (2017)United Nations Population Division, World Population Prospects. https://data.worldbank.org/ indicator/SP.ADO.TFRT

3. Borja JB, Adair LS. Assessing the net effect of young maternal age on birthweight. Am J Hum Biol. 2013;15(6):733-40.

4. Khashan AS, Baker PN, Kenny LC. Preterm birth and reduced birthweight in first and second teenage pregnancies: a registerbased cohort study. BMC Pregnancy Childbirth. 2010;10:36.

5. WHO (2013) The prevention and management of of unsafe abortion. Report of the technical working group. Available at: http://whqlibdoc.who.net/hq. [Accessed 1 April 2015].

6. UNFPDA (2013) Adolescent pregnancy: a review of the evidence. New York, NY: United Nations Population Fund

7. Guomundsdottir E (2015). Risk factors leading to teenage pregnancy. J Fam Plann Reprod Health 6:213.
8. World population data sheet, Population Reference Bureau (PRB) (April, 2016) Adolescent girls in Egypt.5:12.

9. EDHS (2014) Adolescent health in Egypt, Egypt Demographic Health Survey by Elzanaty and Associates. Cairo, Egypt: Ministry of Health.

10. Gandhi P, Sharm S, Rahul G (2014). A study of teenage pregnancies in rural areas. Indian J Appl Sci 4:200.

11. Smith GC, Pell JP. Teenage pregnancy and risk of adverse perinatal outcomes associated with first and second births: a populationbased retrospective cohort study. BMJ. 2001;323(7311):476.

12. Mahavarkar SH, Madhu CK, Mule VD. A comparative study of teenage pregnancy. J Obstet Gynaecol. 2008;28(6):604-7.

13. Bonell C, Allen E, Strange V, Copas A, Oakley A, Stephenson J, et al. The effect of dislike of school on the risk of teenage pregnancy: testing of hypotheses using longitudinal data from a randomized trial of sex education. J Epidemiol Community Health. 2005;59(3):223-30.

14. El-Henawy A. Current situation, progress and prospects of health for all in Egypt. East Mediterr Health J. 2000;6(4):816-21.

15. Rasheed S, Abdelmonem A, Amin M. Adolescent pregnancy in Upper Egypt. Int $\mathbf{J}$ Gynaecol Obstet. 2011;112(1):21-4.

16. Elfenbein DS, Felice ME. Adolescent pregnancy. Pediatr Clin North Am. 2003;50(4):781-800, viii.

17. Gilbert W, Jandial D, Field N, Bigelow P, Danielsen B. Birth outcomes in teenage pregnancies. J Matern Fetal Neonatal Med. 2004;16(5):265-70.

18. Adam GK, Elhassan EM, Ahmed AM, Adam I. Maternal and perinatal outcome in teenage pregnancies in Sudan. Int J Gynaecol Obstet. 2009;105(2):170-1.

19. Conde-Agudelo A, Belizan JM, Lammers C. Maternal-perinatal morbidity and mortality associated with adolescent pregnancy in Latin America: Cross-sectional study. Am J Obstet Gynecol. 2005;192(2):342-9.

20. Smith DM, Roberts R. Social inequality and young pregnancy: the causal attributions of young parents in London, UK. Health Place. 2011;17(5):1054-60. 
21. Fathalla MF. Health and being a mother in the twenty-first century. Int J Gynaecol Obstet. 2007;98(3):195-9.

22. Watcharaseranee N, Pinchantra P, Piyaman $\mathrm{S}$. The incidence and complications of teenage pregnancy at Chonburi Hospital. J Med Assoc Thai. 2006;89 Suppl 4: S118-23.

23. Figueiredo B, Bifulco A, Pacheco A, Costa R, Magarinho R. Teenage pregnancy, attachment style, and depression: a comparison of teenage and adult pregnant women in a Portuguese series. Attach Hum Dev. 2006;8(2):123-38.

24. Al-Ramahi M, Saleh S. Outcome of adolescent pregnancy at a university hospital in Jordan. Arch Gynecol Obstet. 2006;273(4):207-10.

25. Kongnyuy EJ, Nana PN, Fomulu N, Wiysonge SC, Kouam L, Doh AS. Adverse perinatal outcomes of adolescent pregnancies in Cameroon. Matern Child Health J. 2008;12(2):149-54.

26. Ziadeh S. Obstetric outcome of teenage pregnancies in North Jordan. Arch Gynecol Obstet. 2001;265(1):26-9.
27. Yildirim $Y$, Inal MM, Tinar $S$. Reproductive and obstetric characteristics of adolescent pregnancies in Turkish women. $\mathbf{J}$ Pediatr Adolesc Gynecol. 2005;18(4):249-53.

28. Maryam K, Ali S. Pregnancy outcome in teenagers in East Sauterne of Iran. J Pak Med Assoc. 2008;58(10):541-4.

29. Chen XK, Wen SW, Fleming N, Yang Q, Walker MC. Increased risks of neonatal and postneonatal mortality associated with teenage pregnancy had different explanations. J Clin Epidemiol. 2008;61(7):688-94.

30. Chen XK, Wen SW, Fleming N, Yang Q, Walker MC. Teenage pregnancy and congenital anomalies: which system is vulnerable? Hum Reprod. 2007;22(6):1730-5.

31. Chen XK, Wen SW, Fleming N, Demissie K, Rhoads GG, Walker M. Teenage pregnancy and adverse birth outcomes: a large population-based retrospective cohort study. Int J Epidemiol.2007; 36(2):368-73.

32. Ali M, Lulseged S. Factors influencing the adolescent birth outcome. Ethiop Med J. 1997;35(1):35-42 